IVAN TAMAKI MONTEIRO DE CASTRO

O desenvolvimento do direito à moradia no direito internacional e sua previsão e efetivação no Brasil

Dissertação de Mestrado

Orientador: Professor Titular Dr. Dalmo de Abreu Dallari

UNIVERSIDADE DE SÃO PAULO

FACULDADE DE DIREITO

São Paulo - SP 
IVAN TAMAKI MONTEIRO DE CASTRO

O desenvolvimento do direito à moradia no direito internacional e sua previsão e efetivação no Brasil

Dissertação apresentada a Banca Examinadora do Programa de Pós-Graduação em Direito, da Faculdade de Direito da Universidade de São Paulo, como exigência parcial para obtenção do título de Mestre em Direito, na área de concentração Direitos Humanos, sob orientação do Prof. Titular Dr. Dalmo de Abreu Dallari.

UNIVERSIDADE DE SÃO PAULO

FACULDADE DE DIREITO

São Paulo - SP 
Catalogação da Publicação

Serviço de Biblioteca e Documentação

Faculdade de Direito da Universidade de São Paulo

Tamaki Monteiro de Castro, Ivan

$\mathrm{O}$ desenvolvimento do direito à moradia no direito internacional e sua previsão e efetivação no Brasil / Ivan Tamaki Monteiro de Castro ; orientador Dalmo de Abreu Dallari -- São Paulo, 2018.

$116 \mathrm{p}$.

Dissertação (Mestrado - Programa de Pós-Graduação em Direitos Humanos) - Faculdade de Direito, Universidade de São Paulo, 2018.

1. Direitos Humanos. 2. Direito à moradia. I. de Abreu Dallari, Dalmo, orient. II. Título. 


\title{
RESUMO
}

CASTRO, Ivan Tamaki Monteiro de. O desenvolvimento do direito à moradia no direito internacional e sua previsão e efetivação no Brasil. 2018. XX páginas. Mestrado Faculdade de Direito, Universidade de São Paulo, São Paulo, janeiro de 2018.

A presente dissertação tem por objetivo analisar o desenvolvimento do marco normativo do direito à moradia no direito internacional e sua recepção no Brasil. Para tanto, foi utilizada pesquisa bibliográfica e documental, com enfoque metodológico qualitativo. A pesquisa documental foi realizada por meio de levantamento e análise de documentos oficiais (tratados, convenções, declarações, leis, decretos), bem como de publicações governamentais e de organismos internacionais. Com isso, buscou-se compreender como ocorreu a transformação do direito à moradia no ordenamento jurídico internacional, para, posteriormente, analisar o movimento de internalização desse direito no ordenamento pátrio.

Palavras-chave: Direitos Humanos. Direito à Moradia.

\begin{abstract}
CASTRO, Ivan Tamaki Monteiro de. The development of the right to housing in international law and its recognition and fulfillment in Brazil. 2018. XXX pages. Master Faculty of Law, University of São Paulo, São Paulo, January of 2018.

This dissertation aims to analyze the development of the normative framework of the right to housing in international law and its reception in Brazil. For that, bibliographical and documentary research was used, with a qualitative methodological approach. Documentary research was conducted through the collection and analysis of official documents (treaties, conventions, declarations, pieces of legislation, decrees), as well as publications by governments and international organizations. The aim of this study was to understand how the transformation of the right to housing occurred in the international legal order, in order to analyze afterwards the movement of its internalization in the Brazilian legal order.
\end{abstract}

Keywords: Human Rights. Right to Housing. 


\section{LISTA DE SIGLAS}

$\begin{array}{ll}\text { AGNU } & \text { Assembleia Geral das Nações Unidas } \\ \text { CCJ } & \text { Comissão de Constituição e Justiça } \\ \text { CCJC } & \text { Comissão de Constituição e Justiça e Cidadania } \\ \text { CDC } & \text { Convenção sobre os Direitos da Criança } \\ \text { CDHM } & \text { Comissão de Direitos Humanos e Minorias } \\ \text { CDTM } & \text { Convenção Internacional sobre a Proteção dos Direitos de Todos os } \\ \text { CEDM } & \text { Trabalhadores Migrantes e dos Membros das suas Famílias } \\ & \text { Convenção sobre a Eliminação de Todas as Formas de } \\ \text { CEDR } & \text { Discriminação contra a Mulher } \\ & \text { Convenção Internacional sobre a Eliminação de todas as Formas de } \\ \text { CG } & \text { Discriminação Racial } \\ \text { CPCD } & \text { Comentário Geral } \\ \text { CRE } & \text { Convenção Internacional sobre Direitos das Pessoas com Deficiência } \\ \text { CREDN } & \text { Comissão de Relações Exteriores } \\ \text { CRER } & \text { Comissão de Relações Exteriores e de Defesa Nacional } \\ \text { DUDH } & \text { Convenção Relativa ao Estatuto dos Refugiados } \\ \text { ECOSOC } & \text { Declaração Universal dos Direitos Humanos } \\ \text { EM } & \text { Conselho Econômico e Social } \\ \text { MRE } & \text { Exposição de Motivos } \\ \text { OIT } & \text { Ministério das Relações Exteriores } \\ \text { ONU } & \text { Organização Internacional do Trabalho } \\ \text { PDL } & \text { Organização das Nações Unidas } \\ \text { PEC } & \text { Projeto de Decreto Legislativo } \\ \text { PIDCP } & \text { Proposta de Emenda à Constituição } \\ \text { PIDESC } & \text { Pacto Internacional de Direitos Civis e Políticos } \\ \text { SF } & \text { Pacto Internacional de Direitos Econômicos, Sociais e Culturais } \\ \text { UNESCO } & \text { Senado Federal } \\ & \text { Organização das Nações Unidas para a Educação, a Ciência e a } \\ & \text { Cultura }\end{array}$




\section{SUMÁRIO}

INTRODUÇÃO

CAPÍTULO 1 - O DIREITO À MORADIA NO DIREITO INTERNACIONAL 15

Da CARTA da ONU À DeclaraÇão Universal dos Direitos Humanos 17

A MORADIA NA PROTEÇÃO DE CIVIS E DE REFUGIADOS

DIREITO À MORAdIA NA ORgANIZAÇÃo INTERNACIONAL DO TrabalHO 23

NÃO-DISCRIMINAÇÃO E DIREITO À MORADIA

OS PACTOS INTERNACIONAIS DE DIREITOS HUMANOS

HABITAT I

MULHERES, NÃO-DISCRIMINAÇÃO E DIREITO À MORADIA

ANO INTERNACIONAL DO ABRIGO PARA OS SEM-TETO E A ESTRATÉGIA GlObAL PARA

ABrIGO

AS CRIANÇAS E O DIREITO À MORADIA

TRABALHADORES MIGRANTES E DIREITO À MORADIA 46

O COMITE SOBRE DIREITOS ECONÔMICOS, SOCIAIS E CULTURAIS E O DELINEAMENTO DO

DIREITO À MORADIA

Habitat II E A Agenda Habitat

PESSOAS COM DEFICIÊNCIA E O DIREITO À MORADIA

POVOS INDÍGENAS E DIREITO À MORADIA

Habitat III e a Nova Agenda Urbana

Algumas CONSIDERAÇÕES

CAPÍTULO 2 - A INTERNALIZAÇÃO DO DIREITO À MORADIA NO BRASIL65

DEClaRaÇÃo Universal dos Direitos Humanos

CONVENÇÃO DE GENEBRA DE 1949

CONVENÇÃO RELATIVA AO ESTATUTO DOS REFUGIADOS

CONVENÇÕES E RECOMENDAÇÕES DA OIT

CONVENÇÃO INTERNACIONAL SOBRE A ELIMINAÇÃO DE TODAS AS FORMAS DE DISCRIMINAÇÃO RACIAL

PACTOS INTERNACIONAIS DE DIREITOS HUMANOS

Direito À MORAdia NA CONSTITUIÇÃo de $1988 \quad 84$

Algumas CONSIDERAÇÕes

CONSIDERAÇÕES FINAIS

REFERÊNCIAS BIBLIOGRÁFICAS $\quad 102$ 


\section{INTRODUÇÃO}

No campo dos direitos sociais, há uma significativa massa crítica do direito à educação, ao passo que a temática do direito à moradia, pelo menos no plano nacional, conta com menos estudos. Existe, não se pretende negar, importante produção acadêmica sobre moradia nos campos da arquitetura e do urbanismo, porém sua interface com os direitos humanos aparece de modo mais restrito. Esta observação pode ser constatada, entre outros, por meio de busca de palavras-chave como "direito à educação", "direito à moradia", "moradia" e "habitação" no Portal de busca integrada do Sistema Integrado de Bibliotecas da Universidade de São Paulo e no Banco de periódicos da Capes.

Dados do relatório World Cities Report mais recente do UN-HABITAT (2016) apontam que, em 2010, cerca de 980 milhões de domicílios urbanos careciam de condições adequadas de moradia. No Brasil, estudo da Fundação João Pinheiro (2017) mostra que em 2015 havia um déficit de mais de 6 milhões de unidades habitacionais. Frente a esse cenário, compreender em que consiste o direito à moradia e como ele se desenvolveu pode contribuir para enfrentar essas enormes carências habitacionais.

O surgimento do direito à moradia tem na criação da Organização das Nações Unidas (ONU) importante elemento que deu condições para que ele pudesse ser promovido e adotado por diversos países no sistema internacional, razão pela qual cabem algumas palavras sobre o surgimento daquela organização internacional.

A experiência coletiva traumática resultante de dois grandes conflitos internacionais no intervalo de uma geração fez com que os Estados buscassem organizar o sistema internacional de modo a garantir a paz e a segurança coletiva (VAÏSSE, 2011). Desse impulso, surgiu a ONU, cuja tônica deveria ser a promoção da solução pacífica das controvérsias e a cooperação internacional (art. 1, itens 1 e 2 da Carta da $\mathrm{ONU}^{1}$ ) no relacionamento entres os Estados. Esta cooperação, cuja finalidade seria "criar condições de estabilidade e bem-estar" (art. 55 da Carta da ONU), favoreceria "o respeito universal e efetivo dos direitos humanos e das liberdades fundamentais para todos, sem distinção de raça, sexo, língua ou religião" (art. 55, alínea "c" da Carta da ONU).

A criação da ONU marca a internacionalização em sentido estrito dos direitos humanos (RAMOS, 2014) ${ }^{2}$, embasando a instituição de um regime de promoção e proteção

1 Promulgado pelo Decreto $\mathrm{n}^{\circ} 19.841$, de 22 de outubro de 1945.

2 A internacionalização em sentido amplo, enquanto propagação de normas de direito internacional, teria ocorrido anteriormente, a partir do século XIX (RAMOS, 2014). Diferentes autores destacam distintos 
dos direitos humanos, o qual viabilizou a adoção de sucessivas resoluções e a assinatura de tratados tendentes a expandir a cobertura dos direitos humanos.

Nesse contexto, destaque-se a assinatura da Declaração Universal dos Direitos Humanos (DUDH) em 1948. A DUDH explicita o conceito de direitos humanos mencionado na Carta da ONU e enuncia uma série de direitos e liberdades cujo respeito seria fundamental para que fosse garantida a dignidade dos seres humanos, que, por sua vez, seria "o fundamento da liberdade, da justiça e da paz no mundo (preâmbulo da Declaração). Na medida em que é resultado da vontade soberana dos Estados, que se comprometem a respeitar esses direitos e a promover seu reconhecimento e observância internacional, a DUDH marca o fim-para alguns autores, pelo menos-do debate especulativo acerca do fundamento dos direitos humanos (BOBBIO, 2004).

No que diz respeito ao objeto deste estudo, a DUDH prevê, no art. 25 (1), que "toda pessoa tem direito a um padrão de vida capaz de assegurar a si a sua família saúde e bemestar, inclusive alimentação, vestuário, habitação, cuidados médicos e serviços sociais indispensáveis...” (grifou-se).

Posteriormente, aprofundando os direitos previstos na DUDH, foram adotados o Pacto Internacional sobre Direitos Civis e Políticos (PIDCP) e o Pacto Internacional sobre Direitos Econômicos, Sociais e Culturais (PIDESC), ambos de $1966^{3}$. A natureza de tratados internacionais os dota de força vinculante mais evidente do que aquela da DUDH, que não é tratado, mas declaração adotada no âmbito da Assembleia Geral da ONU ${ }^{4}$.

Quanto ao direito à moradia, o PIDCP aborda a questão de maneira indireta no art. 17, prevendo que "ninguém poderá ser objetivo de ingerências arbitrárias ou ilegais em sua vida privada, em sua família, em seu domicílio ou em sua correspondência” (grifou-se).

O PIDESC, por sua vez, reconhece, em seu art. 11 (1), “o direito de toda pessoa a um nível de vida adequado para si próprio e sua família, inclusive à alimentação,

movimentos que teriam caracterizado esse processo. Ramos (2014), por exemplo, destaca o combate à escravidão, a proteção dos direitos dos estrangeiros, o direito humanitário, a proteção de minorias promovida pela Liga das Nações e a proteção dos direitos trabalhistas pela Organização Internacional do Trabalho. Piovesan (2010), por sua vez, enfatiza o papel do direito humanitário, da Liga das Nações e da Organização Internacional do Trabalho. Já Comparato (2008) destaca o direito humanitário, a luta contra a escravidão e a regulação dos direitos dos trabalhadores assalariados. De qualquer modo, parece haver acordo entre os autores que a criação da ONU e a Declaração Universal dos Direitos Humanos constituem um momento qualitativamente superior em relação ao movimento de internacionalização anterior dos direitos humanos.

3 Promulgados, respectivamente, pelos Decretos no 592 e 591, ambos de 6 de julho de 1992.

4 RAMOS (2014) identifica três vertentes teóricas acerca da força vinculante da DUDH: i) possui força vinculante por constituir interpretação autêntica do termo "direitos humanos", previsto na Carta da ONU; ii) possui força vinculante por representar o costume internacional e iii) constitui conjunto de normas não vinculantes, objetivando orientar a ação dos Estados. 
vestimenta e moradia adequadas, assim como a uma melhoria continua de suas condições de vida" (grifou-se). Dessa maneira, o direito à moradia passa a ser compreendido como um componente do direito a um padrão de vida adequado, o que é fundamental para o desenvolvimento do ser humano e o gozo de outros direitos civis, políticos, econômicos, sociais e culturais.

$\mathrm{O}$ direito à moradia foi refinado por meio de manifestações do Comitê sobre Direitos Econômicos, Sociais e Culturais, corpo de especialistas independentes criado pelo Conselho Econômico e Social das Nações Unidas (ECOSOC) $)^{5}$ para monitorar a implementação do PIDESC pelos Estados-membros. O Comentário Geral $n^{\circ} 4\left(\mathrm{CG} \mathrm{n}^{\mathrm{o}} 4\right)$ daquele comitê, por exemplo, estabelece que o direito à moradia não deve ser interpretado de maneira restritiva (no sentido de apenas abrigo), mas deve ser entendido como o direito a viver em segurança, paz e com dignidade (parágrafo 7), uma vez que ele está intimamente ligado a outros direitos humanos e princípios fundamentais que embasam o PIDESC.

$\mathrm{O} C G \mathrm{n}^{\circ} 4$ lança luz acerca da questão da adequabilidade, fundamental para compreender o que constituiria uma moradia adequada, núcleo do direito previsto no art. 11 (1) do PIDESC. Nesse sentido, o direito à moradia adequada deve considerar os seguintes elementos: segurança jurídica da posse; disponibilidade de serviços, materiais, instalações e infraestrutura; acessibilidade econômica; habitabilidade; acesso à moradia e à terra; localização e adequação cultural (parágrafo 8).

Ademais, outros tratados internacionais possuem previsões atinentes ao direito à moradia, dentre os quais destacamos: a Convenção sobre o Estatuto dos Refugiados (1951), a Convenção Internacional sobre a Eliminação de todas as Formas de Discriminação Racial (1965), a Convenção sobre a Eliminação de Todas as Formas de Discriminação contra a Mulher (1979), a Convenção sobre Direitos das Crianças (1989), a Convenção Internacional sobre a Proteção dos Direitos de Todos os Trabalhadores Migrantes e dos Membros das suas Famílias (1990) e a Convenção Internacional sobre os Direitos das Pessoas com Deficiência (2006).

Além dos instrumentos acima citados, o direito à moradia adequada figurou nos debates - materializando-se nas respectivas declarações e planos de ação-das Conferências das Nações Unidas sobre Assentamentos Humanos (Habitat I, II e III) ${ }^{6}$,

5 Resolução 1985/17, de 28 de maio de 1985.

6 De modo geral, as declarações reafirmam o compromisso dos Estados com a realização completa e progressiva do direito à moradia adequada. Aspectos particulares sobre da evolução do direito à moradia 
realizadas em Vancouver (1976), Istambul (1996) e Quito (2016).

$\mathrm{O}$ quadro da promoção do direito à moradia adequada no âmbito internacional conta ainda com o Programa das Nações Unidas para Assentamentos Humanos (UNHabitat) e a Relatoria Especial da ONU para o Direito à Moradia Adequada.

Para que seja possível passar da previsão dos direitos humanos para sua efetiva proteção, faz-se necessário que as normas de direito internacional dos direitos humanos sejam plenamente integradas no ordenamento jurídico interno (PIOVESAN, 2010). No que diz respeito particularmente aos direitos sociais, sua efetivação depende ainda de uma ação positiva do Estado, ao qual dá-se o nome de política pública (HÖFLING, 2001). No Brasil, este processo ocorreu por meio da incorporação de tratados internacionais, pela elaboração de normas e pela implementação de políticas públicas tendentes a efetivar o direito à moradia adequada.

A Constituição Federal de 1988 (CF/88), em seu artigo 6º , estabelece a moradia como direito social. Note-se que o direito à moradia não figurava no texto original, promulgado em 1988, tendo sido adicionado pela Emenda Constitucional $\mathrm{n}^{\circ} 26$, de 14 de fevereiro de 2000.

A previsão do direito à moradia na Constituição não é desprovida de consequência. A própria $\mathrm{CF} / 88$ estabelece que "as normas definidoras dos direitos e garantias fundamentais têm aplicação imediata" (art. $5^{\circ}$, parágrafo $1^{\circ}$ ). Segundo Sarlet:

"De qualquer modo, com a recente inclusão no rol dos direitos fundamentais sociais, a possível controvérsia quanto ao reconhecimento inequívoco no plano constitucional de um direito à moradia resta superada. Se o direito à moradia, pelos motivos já apontados, não chega a ser propriamente um "novo direito" na nossa ordem jurídicoconstitucional, por certo a sua expressa positivação, ainda mais no mesmo plano dos demais direitos sociais básicos nominados no art. 6 , da $\mathrm{CF}$, the imprime uma especial significação, além de colocar novas dimensões e perspectivas no que diz com a sua eficácia e efetividade, pressupondo-se, à evidência, uma concepção de Constituição que, mesmo reconhecendo - com Luís Roberto Barroso-que o direito (e também o direito constitucional) não deve normatizar o inalcançável—nem por isso deixa de assegurar a aplicabilidade imediata das normas definidoras de direitos e garantias fundamentais." (SARLET, 2008, s/p)

adequada no contexto das conferências serão analisados ao longo do desenvolvimento do trabalho. 
A consagração do direito à moradia na Constituição possibilita que sejam utilizados remédios constitucionais nos casos de sua não efetivação. Um levantamento preliminar sobre a questão, entretanto, parece indicar que a discussão judicial acerca da matéria concentra-se no aspecto negativo do direito à moradia (SARLET, 2008). Para a garantia do direito à moradia faz-se necessária a formulação de demandas- políticas $^{7}$ e judiciais— também centradas no aspecto positivo deste direito.

No tocante às responsabilidades pela efetivação do direito à moradia, a CF/88 estabelece a partilha das competências entre os respectivos entes federativos. Assim, compete à União "instruir diretrizes para o desenvolvimento urbano, inclusive habitação, saneamento básico e transportes urbanos" (art. 21, inc. XX). A promoção de "programas de construção de moradia e melhoria das condições de habitacionais e de saneamento básico" (art. 23, inc. IX), por sua vez, é competência comum da União, dos Estados, do Distrito Federal e dos Municípios.

O presente estudo justifica-se, primeiramente, pela dimensão social da carência de moradia adequada no País. Com base nos dados colhidos pela pesquisa nacional por amostra de domicílios (Pnad) de 2015, estima-se o déficit habitacional ${ }^{8}$ em mais de 6 milhões de domicílios (FUNDAÇÃO JOÃO PINHEIRO, 2017). O déficit vem crescendo, com aumento significativo nas regiões metropolitanas de São Paulo, Rio de Janeiro, Belo Horizonte e Curitiba, o que acabou por impactar os resultados dos respectivos estados nas estatísticas.

O déficit habitacional evidencia, ainda, um forte aspecto da desigualdade social que ainda marca a sociedade brasileira:

“Em 2012, aproximadamente 74\% do déficit era composto por famílias em domicílios com renda de até três salários mínimos, um aumento de $4 \%$, se comparado aos valores observados em 2007. Houve redução para as demais faixas: (i) o estrato com renda domiciliar entre três e cinco salários mínimos apresentou redução de $11,5 \%$ no período; (ii) no de renda domiciliar entre cinco e dez salários mínimos houve um decréscimo de cerca de $10 \%$ na sua participação do déficit; e, (iii) o de renda domiciliar acima de dez salários mínimos reduziu sua participação

7 Isso parece ser verdadeiro sobretudo se considerado o amplo espectro de medidas necessárias para a efetivação do direito à moradia adequada (tendo em mente as diretrizes da CG $n^{\circ} 4$ ) e a realidade brasileira de desigualdade e concentração fundiária (MARICATO, 2011).

8 Segundo metodologia desenvolvida pela Fundação João Pinheiro-e adotada pelo Ministério das Cidades-, o déficit habitacional considerada quatro componentes: habitação precária, coabitação familiar, ônus excessivo com aluguel e adensamento excessivo em domicílios locados (BRASIL, 2011). 
em cerca de $30 \%$ no período. Isto reitera que o déficit continua sendo majoritariamente dos domicílios que estão no estrato de renda mais baixo. "(FURTADO, KRAUSE e LIMA NETO, 2013, p. 5)

O quadro apresentado quando se considera apenas o déficit habitacional, no entanto, parece subestimar a carência de moradia no Brasil, uma vez que a metodologia utilizada não considera a ausência de saneamento básico, elemento constitutivo do direito à moradia adequada. Segundo estudos do Instituto de Pesquisa Econômica Aplicada, com base em dados de 2006 e considerando apenas as áreas urbanas, são 14,2 milhões de pessoas não possuem água canalizada, 34,5 milhões sem esgoto por rede ou fossa séptica e 4,4 milhões de pessoas sem coleta de lixo (WEGRZYNOVSKI, 2008).

Ademais, recorde-se que o Brasil rege-se em suas relações internacionais pela prevalência dos direitos humanos (art. $4^{\circ}$, inc. II da CF/88). Em consonância com este princípio, o Brasil, como procuramos demonstrar anteriormente, assumiu diversos compromissos internacionais no sentido de promover a efetivação do direito à moradia adequada. Nesse sentido, este estudo pode contribuir para compreender em que medida o País está cumprindo com seus deveres em uma seara de relevante repercussão socioeconômica.

Ao longo deste trabalho, procuraremos analisar a transformação do reconhecimento internacional do direito à moradia e sua recepção no âmbito nacional. Para que esses objetivos sejam alcançados, pretendemos identificar e estudar os tratados e demais instrumentos normativos acerca da matéria no âmbito internacional, desde a Declaração Universal dos Direitos Humanos (1948), bem como levantar e analisar os mecanismos de incorporação do direito à moradia no âmbito nacional.

Por meio de recurso a fontes secundárias, buscar-se-á fornecer elementos de contextualização histórica dos momentos de adoção dos instrumentos de previsão do direito à moradia. Não temos a pretensão de buscar um sentido profundo na adoção desses intrumentos, como o faz, por exemplo Murphy (2014), que identifica no desenvolvimento do sistema internacional no século $\mathrm{XX}$ a criação de condições para a expansão do capitalismo industrial. Esse aprofundamento analítico poderá ser objeto de agenda de pesquisa futura, a ser desenvolvida no prosseguimento do percurso na pós-graduação.

Para que seja possível atingir os objetivos deste projeto, optouu-se por instrumentos inerentes à metodologia qualitativa de pesquisa (DESLAURIERS e KÉRISIT, 2008). Esta abordagem parece a mais adequada para que a análise não seja restritiva, unidimensional, mas abarque conhecimentos de outras Ciências Sociais (Sociologia, Política, História, 
Urbanismo) que não apenas o Direito, haja vista "a natureza socialmente construída da realidade, a íntima relação entre o pesquisador e o que é estudado, e as limitações situacionais que influenciam a investigação” (DENZIN e LINCOLN, 2006, p. 23).

Ciente de que a pesquisa qualitativa é denominação que abarca diversas concepções, possibilidades de análise, abordagens e métodos investigativos, selecionamos os instrumentos que nos parecem mais apropriados para a compreensão de fenômenos eminentemente sócio-históricos (SANTOS, 1989). Para tanto, seguimos um enfoque interpretativo, buscando compreender as manifestações sob perspectiva de análise histórica e crítica social.

No desenvolvimento da pesquisa, inicialmente, procedeu-se à revisão bibliográfica, que compreendeu levantamento e estudo de publicações (livros, artigos científicos, teses, dissertações, relatórios e documentos oficiais) acerca dos objetos da presente pesquisa. A revisão bibliográfica informou o estado da arte nas discussões acerca do desenvolvimento, previsão e efetivação dos direitos humanos, contribuindo para estabelecer o quadro teórico em que procuraremos localizar a transformação do direito à moradia. Como apontam Deslauriers e Kérisit (2008, p. 41), “à medida que progride a teorização enraizada, a revisão bibliográfica fornece as construções teóricas, categorias e propriedades que servem para organizar os dados e descobrir novas relações entre teoria e mundo real".

Além da revisão bibliográfica, realizou-se pesquisa documental por meio do levantamento e análise de documentos oficiais (tratados, convenções, declarações, leis, decretos), bem como de publicações governamentais e de organismos internacionais. Da análise dos documentos levantados buscamos compreender e descrever como ocorreu a transformação do direito à moradia no ordenamento jurídico internacional, bem como apontar alguns elementos do contexto em que se deu a adoção daquele instrumento Posteriormente, procuraremos analisar o movimento de internalização desse direito no ordenamento pátrio.

Para efeito de delimitação dos objetivos da pesquisa, o levantamento da transformação do direito à moradia no âmbito internacional partirá da Declaração Universal dos Direitos Humanos (1948), o que se justifica pelo fato de a Declaração ser o primeiro documento de ampla aceitação a estabelecer direitos que deveriam ser seguidos pelos Estados pactuantes (BOBBIO, 2004). Esse marco acaba por balizar também o ponto de partida para a análise da incorporação dos tratados no âmbito nacional.

Uma vez composto o quadro da transformação e previsão do direito à moradia no âmbito internacional e nacional, procuraremos confrontar esse marco legal com alguns 
dados sobre a situação da moradia no País para tentar entender como anda a efetivação desse direito. 


\section{Considerações finais}

Como vimos nos capítulos anteriores, o direito à moradia parece relativamente bem desenvolvido no direito internacional, figurando em tratados de caráter geral (pactos internacionais de direitos humanos) e particular (refugiados, trabalhadores, mulheres, crianças, pessoas com deficiência). O Brasil, por sua vez, ratificou a ampla maioria desses instrumentos, estando sujeito ao monitoramento de pelo menos 9 órgãos distintos em relação a diferentes aspectos do direito à moradia, além daquele promovido pelo sistema interamericano de direitos humanos, que não foi objeto deste estudo. Essa profusão legal de instrumentos e a participação brasileira em sua maioria, entretanto, se reflete na efetivação desse direito? Abaixo analisamos alguns aspectos da questão da moradia no Brasil e propomos algumas indicações para refletir acerca da relação entre a promoção e a efetivação desse direito.

Importantes indicadores para aferir o grau de efetivação do direito à moradia no Brasil são o déficit habitacional e a inadequação de moradias. Desenvolvidos pela Fundação João Pinheiro, vinculada ao governo de Minas Gerais, por meio de dados da Pesquisa Nacional por Amostra de Domicílios (PNAD), do Instituto Brasileiro de Geografia e Estatística (IBGE), os indicadores são utilizados oficialmente pelo governo federal e outras esferas de governo. O déficit tem caráter quantitativo e indica a necessidade de construção de novas moradias, ao passo que a inadequação tem perfil qualitativo e aponta problemas nas condições de vida dos moradores e nas especificidades do domicílio urbano, não dizendo respeito ao estoque de habitações.

Os conceitos tem por objetivo oferecer um quadro da realidade brasileira a partir da perspectiva de necessidades habitacionais e fornecer elementos para tomadores de decisão e formuladores de políticas, de modo que não foram desenvolvidos tendo como ponto de partida um abordagem baseada em direitos humanos. Nesse sentido, ainda que se possa utilizar esses dados para compor um panorama das violações do direito à moradia, uma vez que há componentes dos indicadores que correspondem a elementos constituintes desse direito humano segundo o $\mathrm{CG} \mathrm{n}^{\circ} 4$, existem aspectos de adequabilidade que não podem ser mensurados por meio dessas métricas - dos 7 elementos constituintes da adequabilidade da moradia (segurança legal da posse, disponibilidade de serviços e infraestrutura, custo acessível, habitabilidade, acessibilidade, localização e adequação cultural), 4 podem ser avaliados pelos indicadores de déficit habitacional e inadequação de moradias. De qualquer 
modo, este instrumental é o que há de mais apurado para aferir, no Brasil, o estado em que se encontra a efetivação do direito à moradia.

O déficit é calculado pela soma de 4 componentes: a) domicílios precários, b) coabitação familiar, c) ônus excessivo com aluguel urbano e d) adensamento excessivo de domicílios alugados. Dentre os domicílios precários, são considerados os rústicos (sem parede de alvenaria ou madeira aparelhada) e os improvisados (locais ou imóveis que não possuem finalidade residencial mas são utilizados como moradia); as condições de insalubridade e desconforto são uma característica evidente dos primeiros mas também podem aparecer nos segundos (embaixo de pontes e viadutos, por exemplo). Por meio do conceito de domicílios precários podemos aferir o componente de habitabilidade da moradia $\left(\mathrm{CG} \mathrm{n}^{\circ} 4, \S 8, \mathrm{~d}\right)$.

A coabitação compreende os cômodos (domicílios particulares de um ou mais aposentos localizados em casa de cômodo, cortiço, entre outros) e as famílias conviventes secundárias que desejam constituir novo domicílio. $\mathrm{O}$ ônus excessivo com aluguel urbano ocorre quando famílias urbanas com até três salários mínimos de renda familiar comprometem mais de $30 \%$ da renda familiar com aluguel. $\mathrm{O}$ adensamento excessivo em domicílios alugados, por sua vez, importa no número médio superior a três moradores por dormitório. Esses 3 indicadores fornecem elementos para aferir tanto o custo acessível da moradia $\left(\mathrm{CG} \mathrm{n}^{\circ} 4, \S 8, \mathrm{c}\right)$ quanto sua habitabilidade.

A inadequação de moradias, por sua vez, é composta por 5 componentes não mutuamente exclusivos (ou seja, que não podem ser somados sob risco de incorrer em múltipla contagem), quais sejam: carência de infraestrutura, adensamento excessivo de moradores em domicílios próprios, problemas fundiários, cobertura inadequada e ausência de unidade sanitária exclusiva.

A carência de infraestrutura abarca os domicílios que não contam com ao menos 1 de 4 serviços básicos: iluminação elétrica, rede de abastecimento de água com canalização interna, rede de esgoto ou fossa séptica e coleta de lixo. Esse componente corresponde precisamente ao aspecto "disponibilidade de serviços, materiais, facilidades e infraestrutura" da adequabilidade da moradia, o qual considera o acesso à energia, água, saneamento e tratamento de esgoto e depósito de lixo $\left(\mathrm{CG} \mathrm{n}^{\circ} 4, \S 8, \mathrm{~b}\right)$.

$\mathrm{O}$ adensamento excessivo leva em conta os domicílios próprios em que haja um número médio de moradores-da família principal, uma vez que aqueles da família secundária já figuram no indicador do déficit habitacional—superior a 3 por dormitório. Assim como ocorre com o adensamento excessivo de domicílios alugados, o adensamento 
de domicílios próprios indica uma privação do direito à moradia na medida em que as pessoas sem veem obrigadas a coabitar em razão da ausência de custo acessível. A coabitação com várias outras pessoas também pode afetar as condições de habitabilidade.

Os problemas fundiários consideram os casos em que ao menos um dos moradores possui a propriedade da moradia mas não a do terreno ou de sua fração ideal. A fragilidade legal da posse pode ensejar despejos forçados bem como outras ameaças e pressões aos moradores, razão pela qual a segurança legal da posse deve ser resguardada para garantir o gozo do direito à moradia $\left(\mathrm{CG} \mathrm{n}^{\circ} 4, \S 8, \mathrm{a}\right)$.

A cobertura inadequada considera os domicílios que possuem telhado de madeira aproveitada, zinco, lata ou palha, circunstâncias que sujeitam os moradores a intempéries, comprometendo assim as condições de habitabilidade. Outra questão que também impacta negativamente nesse quesito é a ausência de unidade sanitária exclusiva.

Os dados mais atualizados disponíveis são aqueles referentes aos anos de 2013 e 2014 (FUNDAÇÃO JOÃO PINHEIRO, 2016), para o déficit habitacional e a inadequação de moradias, e de 2015 (FUNDAÇÃO JOÃO PINHEIRO, 2017), este apenas referente ao déficit $^{65}$. Os relatórios tem por base as últimas PNADs, de 2014 e 2015 respectivamente.

O déficit habitacional vem crescendo no Brasil, passando de 5,846 milhões de domicílios em 2013 para 6,068 milhões em 2014 e 6,186 milhões em 2015. Em relação ao estoque de domicílios particulares permanentes e improvisados, o déficit passou de $9 \% \mathrm{em}$ 2013 e 2014 para 9,3\% em 2015. A ligeira redução do déficit rural foi acompanhada pelo crescimento do componente urbano, que passou de 5,010 milhões de unidades $(85,7 \%$ do déficit) em 2013 para 5,315 milhões em 2014 (87,6\% do déficit) e 5,414 milhões em 2015 (87,5\% do déficit).

O maior déficit habitacional absoluto encontra-se no Sudeste, que passou de 2,246 milhões de unidades em 2013 (38,4\% do déficit do país) para 2,425 milhões em 2014 (40\% do déficit) e 2,430 milhões em 2015. Na região, o Estado de São Paulo concentra a maior parte da carência de unidades, que cresceu de 1,254 milhão em 2013 para 1,327 milhão em 2014 e teve pequena queda para 1,306 milhão em 2015. Dentro do Estado, cerca de metade desse déficit encontra-se na Região Metropolitana de São Paulo (RMSP): 629 mil unidades em 2013, 625 mil em 2014 e 623 mil em 2015.

Dentre os componentes do déficit, o mais importante é o ônus excessivo com

65 Todos os dados abaixo foram retirados desses 2 estudos. Na medida em que o relatório de 2017, referente à PNAD de 2015, ainda apresenta resultados preliminares, alguns dados abarcarão apenas os anos de 2013 e 2014. 
aluguel, cuja participação no total era de $43,7 \%$ em 2013, tendo crescido para 48,2\% em 2014 e $51,1 \%$ em 2015.

A esse elevado déficit de habitações se contrapõe a estimativa do número de domicílios vagos, que seria de 7,230 milhões de unidades em 2013 e 7,241 milhões em 2014 (79\% das unidades em áreas urbanas e 21\% em áreas rurais em ambos os anos).

A inadequação de domicílios apresenta também dados preocupantes. Dentre os componentes do indicador, a carência de infraestrutura é a que mais aparece, contabilizando 11,092 milhões de moradias em 2013 e 11,275 milhões em 2014, o que corresponde a 19,5\% do total de domicílios particulares permanentes urbanos no Brasil. Entre as regiões, o Nordeste conta com o maior número absoluto, 4 milhões de domicílios em 2014, seguido pelo Sudeste, com 2,092 milhões. Em termos relativos, o destaque negativo é a região Norte, que possui $51,5 \%$ dos domicílios carentes em ao menos um dos serviços de infraestrutura considerados.

Dentre os componentes da carência de infraestrutura, chama atenção a falta de esgotamento sanitário, que diminuiu de 2013 para 2014 mas ainda continua muito elevada, indo de 8,519 domicílios para 7,723 milhões.

O segundo maior critério de inadequação é a advinda de problemas fundiários, que atingem 1,888 milhão de unidades ou 3,3\% dos domicílios particulares permanentes urbanos em 2014. O problema afeta majoritariamente a região Sudeste, com 1,119 milhão de unidades, com o Estado de São Paulo respondendo por 637 mil domicílios e a RMSP por 434 mil unidades.

A ausência de banheiro exclusivo e a cobertura inadequada atinge 236 mil e 938 mil domicílios respectivamente em 2014, ao passo que o adensamento excessivo em domicílios próprios abarca 958 mil domicílios em 2014, 485 mil dos quais na região Sudeste.

Se a inadequação de domicílios pode servir para avaliar os desafios na implementação do direito à moradia, a adequação de domicílios pode indicar aspectos positivos na efetivação desse direito. São considerados adequados os domicílios urbanos que não se enquadram nas categorias de déficit ou inadequação; segundo dados da Fundação João Pinheiro (2016), em 2014 dos 57,937 milhões de domicílios particulares permanentes urbanos, 43,315 milhões eram considerados adequados (74,6\%). A região Sudeste concentra a maior parte dos domicílios urbanos, 27,402 milhões, 85,8\% dos quais tidos como adequados. 
Os números apresentam a dimensão do desafio para a efetivação do direito à moradia no Brasil. Debatendo sobre a questão do fundamento dos direitos humanos, Bobbio (2014) defende que não se tratava mais de especular acerca de suas bases, mas que a preocupação agora deveria ser com sua garantia. Pelo que pudemos constatar, o direito à moradia conta com suficiente previsão legal e interpretação realizada por organismos com legitimidade para tanto.

A formulação e implementação de políticas públicas pelo Estado nem sempre tem-necessariamente - por base uma abordagem fundamentada em direitos humanos. Uma indicação disso é o debate que resultou no Programa Minha Casa, Minha Vida (PMCMV). O Ministério das Cidades (MCidades) vinha formulando e debatendo juntamente com a sociedade civil a elaboração de um Plano Nacional de Habitação (Planhab); o estouro da crise internacional de 2008 gerou uma demanda pela implementação de políticas anticíclicas que pudessem contrabalançar os efeitos da crise e sustentar a geração de emprego e a atividade econômica ${ }^{66}$. O Ministério da Fazenda, dialogando com o setor da construção civil, criou o PMCMV, sem a participação do MCidades e ignorando os debates e formulações em torno do Planhab, que acabou esquecido (AMORE, 2015; BONDUKI, 2014).

As implicações do fato de o PMCMV ser mais um programa econômico do que um programa habitacional — destinado a garantir o direito à moradia—podem ser vistas na avaliação de seus resultados. Se houve um inegável aumento do estoque de moradias, com a contratação e a construções de milhões de unidades, o próprio objetivo do programa de combater o déficit habitacional $^{67}$ foi questionado desde seu lançamento. Na primeira fase, a meta de construção de 400 mil unidades para a faixa 1 correspondia à destinação de $40 \%$ das unidades previstas para o espectro que concentrava $90 \%$ do déficit habitacional (AMORE, 2015; MARICATO, 2009), o que indica a baixa aderência do programa ao déficit. Na segunda fase do PMCMV, a previsão é que $60 \%$ das unidades sejam destinadas à faixa 1 , o que ainda demonstra que parte do programa tem canalizado recursos a setores já atendidos pela produção habitacional de mercado.

A utilização privilegiada de uma única forma de combate ao déficit habitacional também tem sido alvo de críticas (BONDUKI, 2014; FERREIRA, 2012; MARICATO,

${ }^{66}$ Setor que movimenta cadeias a montante (equipamentos, insumos e materiais de contrução) e a jusante (móveis e eletrodomésticos), o estímulo à construção civil tem grande capacidade de manutenção do emprego e da renda, aspectos desejáveis em contexto de crise econômica.

67 Segundo metodologia desenvolvida pela Fundação João Pinheiro-e adotada pelo Ministério das Cidades-, o déficit habitacional considerada quatro componentes: habitação precária, coabitação familiar, ônus excessivo com aluguel e adensamento excessivo em domić́lios locados (BRASIL, 2011). 
2009). Medidas de urbanização de favelas e assentamentos precários, recuperação de unidades em áreas centrais e destinação para moradia social e programas de aluguel social para famílias de baixa renda foram deixadas de lado em favor da construção de novas unidades habitacionais, solução de maior impacto econômico e, portanto, mais alinhada com os interesses do setor da construção civil. Nesse sentido, o PMCMV não incorporou a massa crítica produzida acerca da experiência do $\mathrm{BNH}$, uma vez que focou apenas na construção de novas unidades (AMORE, 2015).

Outro aspecto que sugere cerca negligência com considerações de direitos humanos no desenho do programa é o elemento da localização das moradias. A construção em áreas periféricas dos empreendimentos também constitui indício de que o programa não assimilou o balanço da experiência do BNH (BONDUKI, 2014; FERREIRA, 2012; FIX, 2011; MARICATO, 2011). Pesquisas empíricas apontam que o PMCMV vem promovendo a realização de empreendimentos afastados das áreas urbanas consolidadas, reforçando, ao invés de combater, o padrão de segregação socioespacial das cidades brasileiras (BARAVELLI, 2014; MARQUES; RODRIGUES, 2015; ROLNIK et al, 2015). Em determinado momento, todos os empreendimentos na faixa 1 do programa na região metropolitana de São Paulo estavam nas franjas da metrópole, distantes dos empregos e demais infraestruturas urbanas (BARAVELLI, 2014). A análise feita da implementação do programa pela bibliografia consultada demonstra que produção de habitação não vem sendo acompanhada de desenvolvimento urbano.

Como pudemos ver anteriormente, a efetivação do direito à moradia adequada é muito mais ampla do que a mera construção de unidades habitacionais e deve considerar a disponibilidade de serviços, materiais, instalações e infraestrutura (CG $\left.{ }^{\circ} 4\right)$. Desse modo, a provisão de moradia não deveria ocorrer em qualquer lugar, mas deveria observar uma localização apropriada, inserida na rede consolidada da cidade, devidademente provida de infraestrutura e fontes de emprego. Particularmente no que diz respeito à localização periférica dos conjuntos habitacionais, o programa parece repetir aspecto muito criticadoe estudado - dos programas habitacionais implementados pelo regime militar (MARICATO, 2011).

Esta pesquisa nos indica que estão dadas as condições jurídicas —entendidas aqui como expressão da vontade soberana de se comprometer perante a comunidade internacional e a sociedade brasileira a obrigar-se a efetivar o direito à moradia — para que o Estado aja no sentido de garantir que todas e todos desfrutem do direito à moradia — não qualquer moradia, mas uma que lhes permita uma vida digna, pacífica e segura, bem como 
possibilite o acesso a bens e serviços e o gozo de outros direitos humanos. Não obstante, segue existindo uma enorme distância entre as previsões legais e sua efetiva implementação. Para que o direito à moradia seja desfrutado por todos, a política tem um papel essencial.

A presença em inúmeros instrumentos internacionais assinados e ratificados pelo Brasil, bem como em declarações de conferências das quais o País participou e aceitou suas resoluções finais, confere ao direito à moradia uma legitimidade que pode ser utilizada como um ativo na disputa política na sociedade pela construção de consensos para a efetivação desse direito social. Podemos supor que o patamar dessa disputa seria outro se esse direito não estivesse embasado em diversos tratados (vinculantes juridicamente).

Os dados aqui apresentados do défitit habitacional e da inadequação de domicílios no Brasil dão a dimensão do desafio. De seu enfrentamento, entretanto, depende o gozo de uma vida digna de milhões de pessoas. Como em outras situações da vida social, vale aqui o mote tornado célebre por Gramsci: pessimismo da inteligência, otimismo da vontade. 


\section{REFERÊNCIAS BIBLIOGRÁFICAS}

Legislação:

BRASIL. Decreto $n^{\circ}$ 19.841, de 22 de outubro de 1945. Promulga a Carta das Nações Unidas, da qual faz parte integrante o anexo Estatuto da Corte Internacional de Justiça, assinada em São Francisco, a 26 de junho de 1945, por ocasião da Conferência de Organização Internacional das Nações Unidas. Rio de Janeiro, 22 de outubro de 1945.

. Decreto $\mathrm{n}^{\mathrm{o}} 25.696$, de 20 de outubro de 1948. Manda executar os Atos firmados em Montreal, a 09 de outubro de 1946, por ocasião da 29. '. Sessão da Conferência Geral da Organização Internacional do Trabalho. Rio de Janeiro, 20 de outubro de 1948.

Decreto $n^{\circ} 42.121$, de 21 de agosto de 1957. Promulga as convenções concluídas em Genebra a 12 de agosto de 1949, destinadas a proteger vítimas de defesa. Rio de Janeiro, 21 de agosto de 1957.

. Decreto $\mathrm{n}^{\mathrm{o}} 50.215$, de 28 de janeiro de 1961. Promulga a Convenção relativa ao Estatuto dos Refugiados, concluída em Genebra, em 28 de julho de 1951. Brasília, 28 de janeiro de 1961.

. Decreto $n^{\circ} 58.824$, de 14 de julho de 1966. Promulga a Convenção $n^{\circ} 107$ sobre as populações indígenas e tribais. Brasília, 14 de julho de 1966.

. Decreto $\mathrm{n}^{\mathrm{o}}$ 58.826, de 14 de julho de 1966. Promulga a Convenção $\mathrm{n}^{\mathrm{o}} 110$ concernente às condições de emprego dos trabalhadores em fazendas. Brasília, 14 de julho de 1966.

. Decreto $\mathrm{n}^{\mathrm{o}}$ 65.810, de 8 de dezembro de 1969. Promulga a Convenção Internacional sobre a Eliminação de todas as Formas de Discriminação Racial. Brasília, 8 de dezembro de 1969.

. Decreto $\mathrm{n}^{\mathrm{o}}$ 66.496, de 27 de abril de 1970. Promulga a Convenção da OIT número 117 sobre Objetivos e Normas Básicas da Política Social. Brasília, 28 de abril de 
1970.

. Decreto $n^{\circ} 67.499$, de 6 de novembro de 1970. Torna pública a denúncia, pelo Brasil, da Convenção da OIT de $n^{0} 110$, Concernente às Condições de Emprego dos Trabalhadores de Fazendas. Brasília, 6 de novembro de 1970.

Decreto $\mathrm{n}^{\mathrm{0}} 70.946$, de 7 de agosto de 1972. Promulga o Protocolo sobre o

Estatuto dos Refugiados. Brasília, 7 de agosto de 1972.

. Decreto $\mathrm{n}^{\mathrm{0}}$ 89.460, de 20 de março de 1984. Promulga a Convenção sobre a Eliminação de Todas as Formas de Discriminação contra a Mulher, 1979. Brasília, 20 de março de 1984.

. Decreto n ${ }^{\circ} 99.710$, de 21 de novembro de 1990. Promulga a Convenção sobre os Direitos da Criança. Brasília, 21 de novembro de 1990.

. Decreto $n^{\circ} 127$, de 22 de maio de 1991. Promulga a Convenção $n^{\circ} 161$, da Organização Internacional do Trabalho - OIT, relativa aos Serviços de Saúde do Trabalho. Brasília, 22 de maio de 1991.

. Decreto $\mathrm{n}^{\mathrm{o}}$ 591, de 6 julho de 1992. Atos Internacionais. Pacto Internacional sobre Direitos Econômicos, Sociais e Culturais. Promulgação. Brasília, 6 de julho de 1992.

. Decreto $\mathrm{n}^{\mathrm{o}}$ 592, de 6 julho de 1992. Atos Internacionais. Pacto Internacional sobre Direitos Civis e Políticos. Promulgação. Brasília, 6 de julho de 1992.

. Decreto $n^{0} 4.377$, de 13 de setembro de 2002. Promulga a Convenção sobre a Eliminação de Todas as Formas de Discriminação contra a Mulher, de 1979, e revoga o Decreto no 89.460, de 20 de março de 1984. Brasília, 13 de setembro de 2002.

. Decreto $\mathrm{n}^{\mathrm{o}}$ 5.051, 19 de abril de 2004. Promulga a Convenção no 169 da Organização Internacional do Trabalho - OIT sobre Povos Indígenas e Tribais. Brasília, 19 de abril de 2004. 
Decreto $\mathrm{n}^{\circ} 6.949$, de 25 de agosto de 2009. Promulga a Convenção Internacional sobre os Direitos das Pessoas com Deficiência e seu Protocolo Facultativo, assinados em Nova York, em 30 de março de 2007. Brasília, 25 de agosto de 2009.

Decreto-lei $n^{0} 7.935$, de 3 de setembro de 1945. Aprova a Carta das Nações Unidas, assinada em São Francisco, a 26 de junho de 1945, da qual faz parte integrante o anexo Estatuto da Corte Internacional da Justiça. Rio de Janeiro, 4 de setembro de 1945.

. Mensagem $n^{\circ}$ 696, de 13 de dezembro de 2010. Submete à consideração do Congresso Nacional texto da Convenção Internacional sobre a Proteção dos Direitos de Todos os Trabalhadores Migrantes e dos Membros das suas Famílias, adotada em 18 de dezembro de 1990, em Sessão da Assembleia Geral das Nações Unidas. Brasília, 15 de dezembro de 2010.

SENADO FEDERAL. Decreto Legislativo $n^{\circ}$ 5, de 1947. Ratifica os textos da nova Constituição da Organização Internacional do Trabalho e da Convenção sobre a Revisão dos Artigos Finais, aprovados pela Conferência Internacional do Trabalho realizada em Montreal. Rio de Janeiro, 26 de agosto de 1947.

. Decreto Legislativo $\mathrm{n}^{\circ} 35$, de 1956. Aprova as Convenções concluídas em Genebra, sob os auspícios do Comitê Internacional da Cruz Vermelha. Rio de Janeiro, 12 de setembro de 1956.

. Decreto Legislativo $n^{\circ} 11$, de 1960. Aprova a Convenção de 25 de julho de 1951, relativa ao Estatuto dos Refugiados, assinada pelo Brasil a 15 de julho de 1952. Brasília, 7 de julho de 1960.

Decreto Legislativo $\mathrm{n}^{\circ} 33$, de 1964. Ratifica nos termos do art. 66, inciso I, da Constituição Federal, a "Convenção relativa às condições de emprego dos trabalhadores em fazendas", concluída em Genebra, em 1958, por ocasião da XLII Sessão da Conferência do Trabalho, ressalvados os artigos 15 e 20, itens 2 e 3, cuja ratificação é denegada com fundamento na autorização da própria Convenção. Brasília, 5 de agosto de 1964. 
Decreto Legislativo $n^{\circ}$ 20, de 1965. Aprova as Convenções de $\mathrm{n}^{\mathrm{o}}$ s. 21, 22, 91, 93, 94, 97, 103, 104, 105, 106 e 107 e rejeita a de $\mathrm{n}^{\mathrm{o}}$ 90, adotadas pela Conferência-Geral da Organização Internacional do Trabalho. Brasília, 30 de abril de 1965.

Decreto Legislativo $n^{0}$ 65, de 1966. Aprova a Convenção no 117, sobre objetivos e normas básicas da política social, adotada a 22 de junho de 1962, por ocasião da $46^{\text {a }}$ Sessão da Conferência Internacional do Trabalho. Brasília, 30 de novembro de 1966.

- Decreto Legislativo $n^{\circ} 23$, de 1967. Aprova a Convenção Internacional sobre a Eliminação de Todas as Formas de Discriminação Racial, adotada pela Resolução no 2106 da Assembleia-Geral das Nações Unidas, de 21 de dezembro de 1965. Brasília, 21 de junho de 1967.

Decreto Legislativo $\mathrm{n}^{\mathrm{o}}$ 93, de 1971. Autoriza o Governo da República Federativa do Brasil a aderir ao Protocolo sobre o Estatuto dos Refugiados, adotado em Nova York, em 31 de dezembro de 1967, e a substituir ressalvas à Convenção de 1951, sobre o mesmo Estatuto. Brasília, 30 de novembro de 1971.

. Decreto Legislativo $\mathrm{n}^{\mathrm{o}}$ 93, de 1983. Aprova o texto da Convenção sobre a Eliminação de Todas as Formas de Discriminação Contra a Mulher, assinado pela República Federativa do Brasil, em Nova York, no dia 31 de março de 1981,

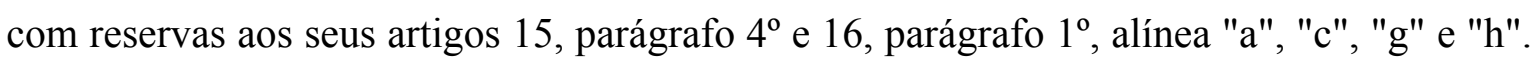
Brasília, 14 de novembro de 1983.

. Decreto Legislativo $\mathrm{n}^{\mathrm{o}}$ 86, de 1989. Aprova os textos das Convenções $n^{\circ}$ s 135 e 161 e rejeita a de nº 143, da Organização Internacional do Trabalho - OIT. Brasília, 14 de dezembro de 1989.

. Decreto Legislativo $\mathrm{n}^{\circ}$ 28, de 1990. Promulga a Convenção sobre os Direitos da Criança. Brasília, 14 de setembro de 1990.

Decreto Legislativo $n^{\circ} 226$, de 1991. Aprova os textos do Pacto 
Internacional sobre Direitos Civis e Políticos e do Pacto Internacional sobre Direitos Econômicos, Sociais e Culturais, ambos aprovados, junto com o Protocolo Facultativo relativo a esse último pacto, na XXI Sessão (1966) da Assembleia-Geral das Nações Unidas. Brasília, 12 de dezembro de 1991.

- Decreto Legislativo $\mathrm{n}^{\mathrm{o}} 26$, de 1994. Aprova o texto da Convenção sobre a Eliminação de Todas as Formas de Discriminação Contra a Mulher, assinado pela República Federativa do Brasil, em Nova Iorque, em 31 de março de 1981, bem como revoga o Decreto Legislativo n 93, de 1983. Brasília, 22 de junho de 1994.

- Decreto Legislativo $\mathrm{n}^{\mathrm{o}} 143$, de 2002. Aprova o texto da Convenção $n^{\circ} 169$ da Organização Internacional do Trabalho sobre os povos indígenas e tribais em países independentes. Brasília, 20 de junho de 2002.

. Decreto Legislativo $\mathrm{n}^{\mathrm{o}} 186$, de 2008. Aprova o texto da Convenção sobre os Direitos das Pessoas com Deficiência e de seu Protocolo Facultativo, assinados em Nova Iorque, em 30 de março de 2007. Brasília, 9 de julho de 2008.

Resoluções de organismos internacionais:

COMMITTEE ON ECONOMIC, SOCIAL AND CULTURAL RIGHTS. General Comment $\mathrm{n}^{\mathrm{o}} 4$ - The right to adequate housing (article 11 (1) of the Covenant). Disponível em:

http://tbinternet.ohchr.org/_layouts/treatybodyexternal/Download.aspx?symbolno=INT\%2f CESCR\%2fGEC\%2f4759\&Lang=en

General

Comment $\mathrm{n}^{0} 7$ - The right to adequate housing: forced evictions (article 11 (1) of the Covenant). Disponível em: http://tbinternet.ohchr.org/_layouts/treatybodyexternal/Download.aspx?symbolno=INT/CE $\underline{\mathrm{SCR} / \mathrm{GEC} / 6430 \& \mathrm{Lang}=\mathrm{en}}$ 
Comment $n^{\circ} 20$ - Non-discrimination in economic, social and cultural (article 2 (2) of the Covenant).

Disponível

em:

http://tbinternet.ohchr.org/_layouts/treatybodyexternal/Download.aspx?symbolno=E/C.12/ GC/20\&Lang=en

COMMITTEE ON THE ELIMINATION OF RACIAL DISCRIMINATION. Opinion Communication $n^{\circ}$ 31/2003. Un doc. CERD/C/66/D/31/2003, 2005.

UNITED NATIONS CONFERENCE ON THE HUMAN ENVIRONMENT. Action Plan for the Human Environment. UN doc. A/Conf.48/14/Rev.1, 1972. Disponível em: https://documents-dds-

ny.un.org/doc/UNDOC/GEN/NL7/300/05/IMG/NL730005.pdf?OpenElement

UNITED NATIONS ECONOMIC AND SOCIAL COUNCIL. Resolution 1982/46 B; UN doc. E/RES/1982/46, 1982. Disponível em: https://documents-ddsny.un.org/doc/RESOLUTION/GEN/NR0/651/76/IMG/NR065176.pdf?OpenElement . Resolution 1985/17 -

Review of the composition, organization and administrative arrangements of the Sessional Working Group of Governmental Experts on the Implementation of the International Covenant on Economic, Social and Cultural Rights. UN doc. E/RES/1985/17. Disponível em:

https://documents-ddsny.un.org/doc/RESOLUTION/GEN/NR0/663/73/IMG/NR066373.pdf?OpenElement

UNITED NATIONS GENERAL ASSEMBLY. Resolution 53 (I) - Housing and town planning. UN doc. A/RES/53(I), 1946. Disponível em: http://www.un.org/en/ga/search/view_doc.asp?symbol=A/RES/53\%28I\%29

- Resolution 217 A (III) - Universal Declaration of Human Rights. UN doc. A/RES/3/217 A, 1948. Disponível em: http://www.un-documents.net/a3r217a.htm

- Resolution 3001 (XXVII) - United

Nations Conference-Exposition on Human Settlements. UN doc. A/RES/27/3001, 1972. 
Disponível em: http://www.un-documents.net/a27r3001.htm

. Resolution 37/221 - International year of shelter for homeless. UN doc. A/RES/37/221, 1982. Disponível em: https://documentsdds-ny.un.org/doc/RESOLUTION/GEN/NR0/426/99/IMG/NR042699.pdf?OpenElement

. Resolution 42/191 - Global strategy for shelter to the year 2000. UN doc. A/RES/42/191, 1987. Disponível em: https://documentsdds-ny.un.org/doc/RESOLUTION/GEN/NR0/514/23/IMG/NR051423.pdf?OpenElement . Resolution 43/180 - International year of shelter for homeless. UN doc. A/RES/43/180, 1988. Disponível em: https://documentsdds-ny.un.org/doc/RESOLUTION/GEN/NR0/531/59/IMG/NR053159.pdf?OpenElement

. United Nations Declaration on the Rights of Indigenous Peoples. UN doc. A/RES/61/295, 2007. Disponível em: http://www.ohchr.org/EN/Issues/IPeoples/Pages/Declaration.aspx

WORLD CONFERENCE ON HUMAN RIGHTS. Vienna Declaration and Programme of Action. $1993 . \quad$ Vienna, em: http://www.ohchr.org/EN/ProfessionalInterest/Pages/Vienna.aspx

Livros e artigos:

AASEN, Henriette Sinding; HELLUM, Anne. Introduction. In: AASEN, Henriette Sinding; HELLUM, Anne (orgs.). Women's human rights: CEDAW in Internacional, Regional and National Law. Cambridge: Cambridge University Press, 2013.

ALFONSIN, Betânia; FERNANDES, Edésio (orgs.). Direito à moradia adequada: o que é, para quem serve, como defender. Belo Horizonte: Fórum, 2014.

ALVES, José Augusto Lindgren. A arquitetura internacional dos direitos humanos. São Paulo: FTD, 1997. 
. Relações internacionais e temas sociais: a década das conferências. Brasília: IBRI, 2001.

ALSTON, Philip (org.). The future of UN human rights treaty monitoring. Cambridge: Cambridge University Press, 2000.

; GOODMAN, Ryan. International human rights. Oxford: Oxford

University Press, 2013.

; QUINN, Gerard. The nature and scope of States parties' obligations under the International Covenant on Economic, Social and Cultural Rights. Human Rights Quarterly, v. 9, nº 2, may, 1987, pp. 156-229.

AMORE, Caio Santo. Minha Casa Minha Vida para iniciantes. In: AMORE, Caio Santo; SHIMBO, Lúcia Zanin; RUFINO, Maria Beatriz Cruz (orgs.). Minha casa...e a cidade? Avaliação do programa Minha Casa Minha Vida em seis estados brasileiros. Rio de Janeiro: Letra capital, 2015.

BARAVELLI, José Eduardo. Trabalho e tecnologia no programa MCMV. Tese de doutorado. São Paulo: FAUUSP, 2014.

BASSUL, José Roberto. Estatuto da cidade: quem ganhou, quem perdeu. Brasília: Senado Federal, 2005.

BILCHITZ, David. Poverty and fundamental rights: the justification and enforcement of socio-economic rights. New York: Oxford University Press, 2007.

BOBBIO, Norberto. A era dos direitos. Rio de Janeiro: Campus, 2004.

BONDUKI, Nabil. Os pioneiros da habitação social. Vol. 1. São Paulo: Editora Unesp, 2014.

BRASIL. INSTITUTO DE PESQUISA ECONÔMICA APLICADA. Políticas sociais: 
acompanhamento e análise. Brasília: IPEA, 2006.

- MINISTÉRIO DAS CIDADES. SECRETARIA NACIONAL DE HABITAÇÃO. Déficit habitacional no Brasil 2008. Brasília: Ministério das Cidades, 2011.

SECRETARIA NACIONAL DE

PROGRAMAS URBANOS. Como produzir moradia bem localizada com os recursos do Programa Minha Casa Minha Vida. Brasília: Ministério das Cidades, s/d.

- MINISTÉRIO DO PLANEJAMENTO, ORÇAMENTO E GESTÃO. $11^{\circ}$

Balanço do PAC 2. Brasília: Ministério do Planejamento, Orçamento e Gestão, 2014. . SECRETARIA DE DIREITOS HUMANOS DA PRESIDÊNCIA DA REPÚBLICA. Direito à moradia adequada. Brasília, 2013.

BUCCI, Maria Paula Dallari. Fundamentos para uma Teoria Jurídica das Políticas Públicas. São Paulo: Saraiva, 2013

CHAPMAN, Audrey; RUSSEL, Sage (orgs.). Core obligations: building a framework for economic, social and cultural rights. Oxford: Intersentia, 2002.

CHOLEWINSKI, Ryszard; GUCHTENEIRE, Paul de; PÉCOUD, Antoine (ed.). Migration and Human Rights: the United Nations Convention on Migrant Worker's Rights. Nova Iorque: Cambridge University Press, 2009.

COMPARATO, Fábio Konder. A afirmação histórica dos direitos humanos. São Paulo: Saraiva, 2008.

CRAVEN, Matthew. History, pre-history and the right to housing in international law. In: LECKIE, Scott (editor). National Perspectives on Housing Rights. The Hague: Martinus Nijhoff, 2003. . The Domestic Application of the International Covenant on Economic, Social and Cultural Rights. Netherlands International Law Review. Volume 40, 
no 3, December 1993, p. 367-404.

. The international covenant on economic, social and cultural rights: a perspective on its development. New York: Oxford University Press, 1998.

CRAWFORD, James; ALSTON, Philip (editors). The future of human rights treaty monitoring. Cambridge: Cambridge University Press, 2000.

DA GUIA, Jorge Alex; MORAIS, Maria da Piedade; PAULA, Rubem de. Monitorando o direito à moradia no Brasil (1992-2004). In: BRASIL. INSTITUTO DE PESQUISA ECONÔMICA APLICADA. Políticas sociais: acompanhamento e análise. Brasília: IPEA, 2006.

DALLARI, Dalmo. Direitos humanos e cidadania. São Paulo: Moderna, 2004.

DENZIN, N. K.; LINCOLN, Y. S. A disciplina e a prática da pesquisa qualitativa. In: (orgs.). O planejamento da pesquisa qualitativa: teorias e abordagens. Porto Alegre: Artmed, 2006.

DESLAURIERS, Jean-Pierre; KÉRISIT, Michele. O delineamento da pesquisa qualitativa. In: POUPART, Jean; DESLAURIERS, Jean-Pierre; GROULX, Lionel-H (Orgs.). A pesquisa qualitativa: enfoques epistemológicos e metodológicos. Petropólis: Vozes, 2008. p. $127-153$.

DONNELLY, Jack. Universal human rights in theory and practice. Ithaca: Cornell University Press, 2003.

FARHA, Leilani. Is there a woman in the House? Re/conceiving the human right do housing. Canadian Journal of Women and the Law. Vol. 14, 2012, pp. 118-136.

FERREIRA, João Sette Whitaker (coord.). Produzir casas ou construir cidades? Desafios para um novo Brasil urbano. São Paulo: Editora Fupam, 2012.

FIX, Mariana de Azevedo Barretto. Financeirização e transformações recentes no circuito 
imobiliário no Brasil. Tese de doutorado. Campinas: IE-UNICAMP, 2011.

FORSYTHE, David P. Encyclopedia of Human Rights. New York: Oxford University Press, 2009.

FREDMAN, Sandra. Engendering socio-economic rights. In: AASEN, Henriette Sinding \& HELLUM, Anne (orgs.). Women's human rights: CEDAW in International, Regional and National Law. Cambridge: Cambridge University Press, 2013.

FUNDAÇÃO JOÃO PINHEIRO. Déficit Habitacional no Brasil - 2013-2014. Belo Horizonte, 2016.

Déficit Habitacional no Brasil - 2015: resultados

preliminares. Belo Horizonte, 2017.

FURTADO, Bernardo Alves; KRAUSE, Cleandro; LIMA NETO, Vicente Correia. Estimativas do déficit habitacional brasileiro (PNAD 2007-2012). Brasília: IPEA, 2013.

GRAHL-MADSEN, Atle. Commentary on the Refugee Convention 1951. Genebra: Division of International Protection of the United Nations High Commissioner for Refugees, 1997. Disponível em: http://www.unhcr.org/publ/PUBL/3d4ab5fb9.pdf

HODGKIN, Rachel; NEWELL, Peter. Implementation handbook for the Convention on the rights of the child. Genebra: UNICEF, 2007.

HÖFLING, Eloísa de Matos. Estado e políticas (públicas) sociais. Cadernos CEDES. ${ }^{\circ}$ 55, ano XXI, 2001. p. 30-41.

LAFER, Celso. A reconstrução dos direitos humanos: um diálogo com o pensamento de Hannah Arendt. São Paulo: Companhia das Letras, 1991.

LECKIE, Scott. From housing needs to housing rights: an analysis of the right to adequate housing under international human rights law. London: International Institute for Environment and Development, 1992. 
. National perspectives on housing rights. The Hague: Martinus Nijhoff Publishers, 2003.

LEE, Eddy. La Déclaration de Philadelphie: rétrospective et prospective. Revue Internationale du Travail, vol. 133, 1994, $\mathrm{n}^{\circ} 4$.

LERNER, Natan. The UN Convention on the elimination of all forms of racial discrimination: a commentary. Leiden: A.W. Sijthoff, 1970.

MAKKONEN, Timo. Equal in law, unequal in fact: racial and ethnic discrimination and the legal response thereto in Europe. 2010. $311 \mathrm{f}$. Tese (Doutorado) - Faculdade de Direito da Universidade de Helsinque, Finlândia.

MARICATO, Erminia. Brasil, cidades: alternativas para a crise urbana. Rio de Janeiro: Vozes, 2001. . O impasse da política urbana brasileira. Rio de Janeiro: Vozes, 2011. . O Ministério das Cidades e a política nacional de desenvolvimento urbano. In: BRASIL. INSTITUTO DE PESQUISA ECONÔMICA APLICADA. Políticas sociais: acompanhamento e análise. Brasília: IPEA, 2006.

. O Minha Casa é um avanço, mas segregação urbana fica intocada. Disponível em: $<$ http://cartamaior.com.br/?/Editoria/Politica/O-Minha-Casa-e-um-avancomas-segregacao-urbana-fica-intocada/4/15160> . Publicado em: 27/05/2009.

MARQUES, Eduardo; RODRIGUES, Leandro. A produção pública de habitação. In: MARQUES, Eduardo (org.). A metrópole de São Paulo no século XXI: espaços, heterogeneidades e desigualdades. São Paulo: Editora Unesp, 2015.

MECHLEM, Kerstin. Treaty bodies and the interpretation of human rights. Vanderbilt Journal of Transnational Law. Vol. 42, 2009. p. 905-947 
MICHALOWSKI, Sabine; MARTIN, Wayne. The legal status of general comments. Essex, 2014. Disponível em: http://autonomy.essex.ac.uk/wpcontent/uploads/2014/07/Legal-status-of-General-Comments-.pdf

MONSINK, Johannes. The universal declaration of human rights: origins, drafting and intent. Philadelphia: University of Pennsylvania Press, 1999.

MULLER, Pierre. Les politiques publiques. Paris: Presses universitaires de France, 2013.

MURPHY, Craig N. Organização internacional e mudança industrial. São Paulo: Editora UNESP, 2014.

OFFICE OF THE UNITED NATIONS HIGH COMMISSIONER FOR HUMAN RIGHTS (OHCHR). The right to adequate housing - fact sheet $n^{\circ} 21$ (rev. 1). Geneva: United Nations, 2014.

ORGANIZAÇÃO DAS NAÇÕES UNIDAS PARA A EDUCAÇÃO, A CIÊNCIA E A CULTURA. Declaração das Nações Unidas sobre os Povos Indígenas: perguntas e respostas. Brasília: UNESCO, 2009.

PILLAY, Navenethem. Strengthening the United Nations human rights treaty body system: a report by the United Nations High Commissioner for Human Rights. Genebra: Office of the High $2012 . \quad$ Disponível em: http://www2.ohchr.org/english/bodies/HRTD/docs/HCReportTBStrengthening.pdf

PIOVESAN, Flávia. Direitos Humanos e o direito constitucional internacional. São Paulo: Saraiva, 2010.

PIOVESAN, Flávia. Direitos sociais, econômicos e culturais e direitos civis e políticos. SUR - Revista Internacional de Direitos Humanos. ${ }^{\circ}$ 1, ano 1, 2004. p. 20-47

POULANTZAS, Nicos. O Estado, o poder, o socialismo. São Paulo: Graal, 2000.

RAMOS, André de Carvalho. Teoria geral dos direitos humanos na ordem internacional. 
São Paulo: Saraiva, 2014.

REIS FILHO, Daniel Araão (coord.). Modernização, ditadura e democracia - 1964-2010. Objetiva: São Paulo, 2014.

REDE CIDADE E MORADIA. Programa Minha Casa Minha Vida deve ser avaliado: nota pública da Rede Cidade e Moradia. 2014. Disponível em: http://www.labcidade.fau.usp.br/arquivos/nota.pdf

REZEK, Francisco. Direito internacional público: curso elementar. $12^{\mathrm{a}}$ edição. São Paulo: Saraiva, 2010.

ROBERTSON, Robert E. Measuring State compliance with the obligation to devote the "maximum available resources" to realising economic, social and cultural rights. Human rights quarterly. Volume 16, nº 4, November 1994, p. 693-714.

ROLNIK, Raquel. A construção de uma política fundiária e de planejamento urbano para o país: avanços e desafios. In: BRASIL. INSTITUTO DE PESQUISA ECONÔMICA APLICADA. Políticas sociais: acompanhamento e análise. Brasília: IPEA, 2006. Late neoliberalism: the financialization of homeownership and housing rights. International Journal of Urban and Regional Research. Volume 37 (3), 2013, p. 1058-1066.

et al. Inserção urbana e a efetivação do direito à moradia adequada: uma avaliação de sete empreendimentos no estado de São Paulo. In: AMORE, Caio Santo; SHIMBO, Lúcia Zanin; RUFINO, Maria Beatriz Cruz (orgs.). Minha casa...e a cidade? Avaliação do programa Minha Casa Minha Vida em seis estados brasileiros. Rio de Janeiro: Letra capital, 2015.

ROYO, Luis Rodríguez-Piñero. "Where appropriate": monitoring/implementing of indigenous peoples' rights under the Declaration. In: CHARTERS, Claire; STAVENHAGEN, Rodolfo (ed.). Making the Declaration work. Copenhagen: Transaction Publishers, 2009. 
SANTOS, Boaventura de Sousa. Introdução a uma ciência pós-moderna. Rio de Janeiro:

Edições Graal, 1989.

SARLET, Ingo Wolfgang. O direito fundamental à moradia aos vinte anos da Constituição Federal de 1988. Revista Brasileira de Estudos Constitucionais. Ano 2, nº 8, 2008

UNITED NATIONS HUMAN SETTLEMENTS PROGRAMME (UN-HABITAT). Compilation of United Nations resolutions on housing rights. Nairobi: United Nations, 2005.

. Housing rights legislation: review of international and national instruments. Nairobi: United Nations, 2002a.

. International instruments on housing rights. Nairobi: United

Nations, 2002b. . Urbanization and Development: emerging futures. Nairobi: United Nations, 2016.

VAÏSSE, Maurice. Les relations internationales depuis 1945. Paris: Armand Colin, 2011.

WEGRZYNOVSKI, Ricardo. Saneamento: tão perto e tão longe das soluções. Desafios do desenvolvimento. Ano 5, ed. 41, 2008.

WEIS, Paul. The refugee convention, 1951: the travaux preparatoires analysed with a commentary. 1990. Disponível em: http://www.unhcr.org/protection/travaux/4ca34be29/refugee-convention-1951-travauxpreparatoires-analysed-commentary-dr-paul.html

ZIMMERMANN, Andreas. The 1951 Convention relating to the status of refugees and its 1967 Protocol: a commentary. Oxford: Oxford University Press, 2011.

ZWINGEL, Susanne. Translating Internacional Women's Rights: the CEDAW Convention in Context. Londres: Palgrave Macmillan, 2016. 